\title{
The relationship between depth, substrate and ecology: a drop video study from the southeastern Australian coast
}

\author{
Irene Michelle WILLIAMS*, Joseph Henry John LEACH \\ Department of Geomatics, The University of Melbourne, Parkville, VIC 3052, Australia \\ Revised 16 August 1999; accepted 20 August 1999
}

\begin{abstract}
The relationship between hard substrate type, depth and ecology has not been widely investigated in Bass Strait, which separates mainland Australia from Tasmania. As this water body is important to the State, a study along the Victorian coastline using an inexpensive Along Track Video (ATV) system, along with equipment to record depths and locations, was implemented. A better understanding of the correlation between hard substrate, depth and ecology was thought to be valuable to enable researchers to determine to what extent the benthic biological communities depend on physical factors. This understanding should improve procedures to predict the seafloor ecology on the basis of geological and oceanographic data. The dominant species assemblages and geomorphology, among other characteristics, were observed and recorded for each transect. In the sites investigated, depth appears to have a greater influence on dominant assemblages than does the type of hard substrate. The study also served to show that inexpensive ATV systems can be successfully used to study macro-sessile marine resources. (c) 1999 Ifremer / CNRS / IRD / Éditions scientifiques et médicales Elsevier SAS
\end{abstract}

\begin{abstract}
Along Track Video (ATV) / marine videography / coastal waters / Victoria / sessile marine resources
Résumé - Relation entre la profondeur, le substrat et l'écologie. Étude vidéo au sud-est de l'Australie. La relation entre le type de substrat dur, la profondeur et l'écologie est mal connue dans le détroit de Bass, entre l'Australie et la Tasmanie. L'importance de ces eaux pour l'État de Victoria est à l'origine d'une étude effectuée le long de la côte sud-est, à l'aide d'un système peu coûteux de suivi vidéo (ATV, Along Track Video) et enregistrement des coordonnées et de la profondeur. Une meilleure connaissance de la relation entre le substrat dur, la profondeur et l'écologie devrait permettre de déterminer dans quelle mesure les communautés biologiques benthiques dépendent des conditions physiques, et d'améliorer les méthodes de prévision de l'écologie benthique à partir des données géologiques et océanographiques. Les communautés dominantes et la géomorphologie, entre autres caractéristiques, ont été observées et enregistrées sur chaque radiale. Sur les sites considérés, les communautés dominantes sont plus marquées par la profondeur que par la nature du substrat dlur. I es résultats montrent aussi que les systèmes ATV sont bien adaptés à l'étude des ressources marines sessiles. (C) 1999 Ifremer / CNRS / IRD / Éditions scientifiques et médicales Elsevier SAS
\end{abstract}

suivi vidéo / vidéographie / eau côtière / Victoria / ressources marines sessiles

\section{INTRODUCTION}

Along Track Video (ATV) involves extracting sequential frames from a continuous strip of video, in much the same way that overlapping aerial images are used. This segmentation of the imagery sequence can help to provide more information and greater detail of the habitat [10]. The number of images required to provide a continuous

* Correspondence and reprints: irene $@$ sunrise.sli.unimelb.edu.au 
coverage of ATV data is determined by the overlap requirements of the project [16], along with the video towing speed. ATV footage has been used to investigate relationships between the benthic habitats, depths and substrate material of the economically important coastal waters of Victoria. This research has also provided a forum for evaluation of the ATV study method for semiquantitative studies of benthic habitat. The technique has been evaluated not only by the results of this semi-quantitative component of the research, but by the potential the work has shown.

Video has often been used as a source of qualitative data by allowing scientists to determine the macro-species composition and abundance. Quantitative data can be obtained using stereo-video systems, however, single videos with ATV analysis methods also have potential in this area. Although stereo systems provide a greater range and accuracy, they are generally priced at more than double the cost of a single video systcm. The additional costs of stereo systems, being primarily the second camera and its housing, can transform the video data collection system from an easily financed system to one that can break the funding budget. ATV data can be collected using a single video camera mounted on a towed body, sled, drop-frame, or a Remotely Operated Vehicle (ROV) or submersible. The entire system can be built for little more than the cost of a camera and housing, making it a good choice for low budget research. The measurements available from single video systems, however, are far more limited than stereo systems in terms of the types of measurements available and the resulting accuracy.

Victoria, on the southeastern coast of Australia, is separated from Tasmania by Bass Strait. Bass Strait covers the continental shelf between mainland Australia and Tasmania, and was inundated during the last post-glacial marine transgression. The majority of the Strait is less than $75 \mathrm{~m}$ deep, with the maximum depth to the continental margin being approximately $100 \mathrm{~m}$. The deepest waters managed by the Victorian State Government are to the east and west of the State where the continental shelf is narrow. Figure I shows a bathymetric map of Bass Strait.

Many Victorians rely on Bass Strait for either economic or recreational reasons, with its usage including shipping, commercial fishing, tourism, oil and gas resources and effluent discharge [6]. Although the importance of the Strait is widely recognised, there is limited information about the habitats or ecology it contains, or about the relationship between substratc type, depth and ccology. Therefore, in 1991 the then State Government requested that the
Land Conservation Council (LCC), a state government advisory body, investigate the coastal waters of Victoria, and make recommendations to protect areas of significant environmental value [5]. For this research, the Marine and Freshwater Resources Institute (MAFRI), another Victorian Government agency, assisted by conducting a study on 14 sites along the Victorian coastline in 1995.

The aim of the study was to make recommendations about how best to manage the competing interests: commercial, recreational and environmental. Research teams looked at the habitats and human usage in areas deemed economically or environmentally important. Data collected by MAFRI in 1995 for the LCC study included hours of video tape intended to ground truth the data from their RoxAnn acoustic system. The MAFRI video data is the data source for the current research on relationships between depth, ecology and substrate type. This study aims to extend the use of data that was initially collected for ground truth, which is a subsequent common use of video technology [9] not initially intended for quantitative analysis.

The current research, which uses the 1995 MAFRI drop video data, is being conducted to provide a better understanding of the correlation between hard substrates, depth and ecology in this region, thereby enabling researchers to determine the extent to which benthic communities depend on physical factors. It is hoped that this understanding will provide improved procedures to predict the seafloor ecology based on geological and oceanographic data in the region.

\section{METHODOLOGY}

\subsection{Sample sites}

The Victorian coastline was split into five zones according to biophysical characteristics, with the aim being to group similar areas to facilitate the planning and management of the environment. Factors considered in the creation of biophysical regions included geology, topology, climate and vegetation [6]. Studies of Victorian coastal waters have identified five major substrate rock types: basalt, granite, limestone, calcarenite and sandstone [6]. The 14 sites sampled in this study were chosen to provide coverage of all five major biophysical zones. The biophysical zones and the study site distributions can be seen in figure 2. Few samples were taken along the western side of zone five, as sand is the predominant substrate in this region. 


\subsection{Data collection}

With correct calibration, photogrammetric methods may be used to obtain measurements of the size and volume of benthic biota [15], along with stereo measurement of fish size and shape, and motion estimates [7]. The processing problems faced depend on the system used and its complexity. Therefore, it is important to investigate the properties of the system from which the data was obtained so that the limitations and assumptions are known a priori.

The ATV system used by MAFRI for their role in the 1995 study was a drop video. A video camera was mounted on a simple metal frame, as shown in figure 3. Other survey components included a Global Positioning System (GPS) receiver for location data, a depth sounder, and a computer for data logging [11]. The survey consisted of 85 deployments to depths of $87 \mathrm{~m}$. The system was lowered to the seafloor and allowed to settle. This ensured the camera was suspended at a known height above the seafloor, thus providing scale for the first image in an ATV sequence. The frame was then raised from the bottom and allowed to drift. The first image in the run provided the scale, to which all subsequent images could then be scaled and oriented. A vertical camera angle was maintained by the drifting motion of the frame in calm waters [15].

\subsection{Data analyses}

The ATV data were used to investigate the relationship between depth, ecology and hard substrate type along the Victorian coastline, consequently soft sediment deployments were eliminated. These soft substrates had no visible flora or fauna, however, armoured sand and shell sites were included as hard substrate types as they are able to act as anchors for sessile benthic species. Sites which were undulating or of questionable camera orientation were also eliminated, resulting in 56 out of 85 deployments being included in the analyses. The hard substrate types identified were granite, basalt, limestone, sand and calcarenite, with their occurrences identified visually from the video

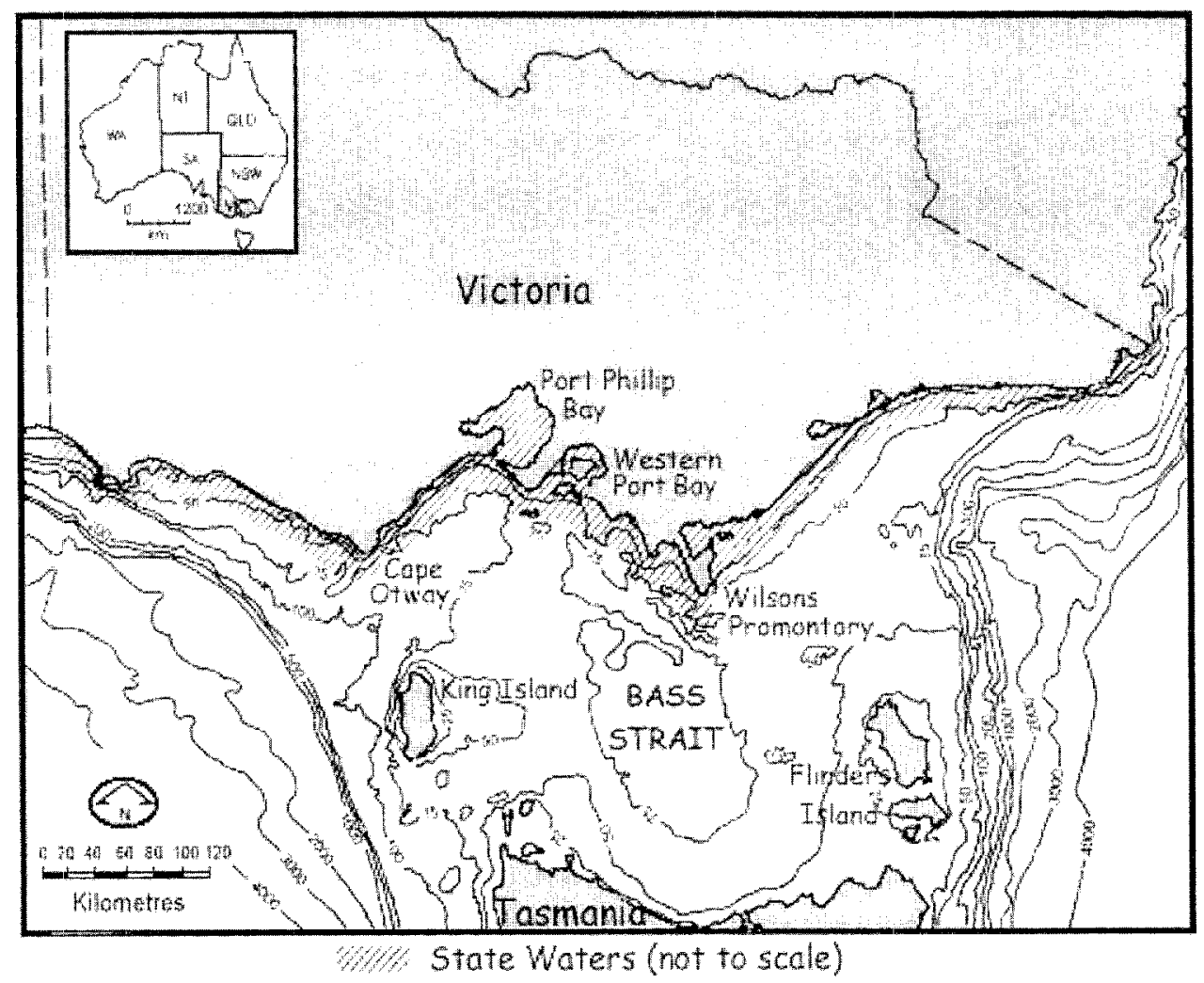

Figure 1. Bathymetric map of Bass Strait. Central coastline extends to the shallow strail, with the eastern and western waters facing onto deeper, oceanic waters. Source: [5]. 




Figure 2. Sample site distribution and substrate types within biophysical zones, source: 16] pp. 53 and 57.

data. Many of the near-shore substrates are believed to be outcrops of coastal geological formations, therefore geological maps of the sample regions were used to verify the conclusions.

The aim of the research was to relate the dominant species to both depth and substrate types in an attempt to determine which factors were important to species occurrence. The species were identified by viewing video and frame grabs, and were placed into dominant assemblages, or groups of species, which are discussed later. In order to provide more information than just the presence or absence of a species, mosaics were used to view the benthic community as a whole. These mosaics were then used to estimate the density of each dominant assemblage. The frequency of each dominant assemblage was graphed against the depth and substrate to allow visual identification of any relationships.

Mosaics made from uncalibrated data sources require assumptions, such as: the imaged site is planar; the camera angle remains fully vertical; and that the lens distortion is minimal. The errors introduced by these assump- tions and the photo-mosaicing process [13] are unknown, therefore, the analysis conducted was semi-quantitative, with the density of the dominant assemblages recorded as sparse (up to $20 \%$ cover), moderate ( $20 \%$ to $60 \%$ cover) or dense ( $60 \%$ to $100 \%$ coverage). To minimise likely error, the measurement sites were selected based on their expected suitability with respect to the assumptions as determined by video observations, with maintenance of vertical camera angle over flat terrain being primary objectives. Although the crrors associatcd with photo-mosaicing are not uniform throughout the mosaic [13], the semi-quantitative nature of this analysis means that the errors introduced by the assumptions made are likely to be absorbed within the ranges of area coverage.

\section{RESULTS}

\subsection{Dominant assemblages}

The dominant assemblages found at the study sites were algac and sponges (examples shown in figure 4). Over 1100 species of marine algae have been recorded along 


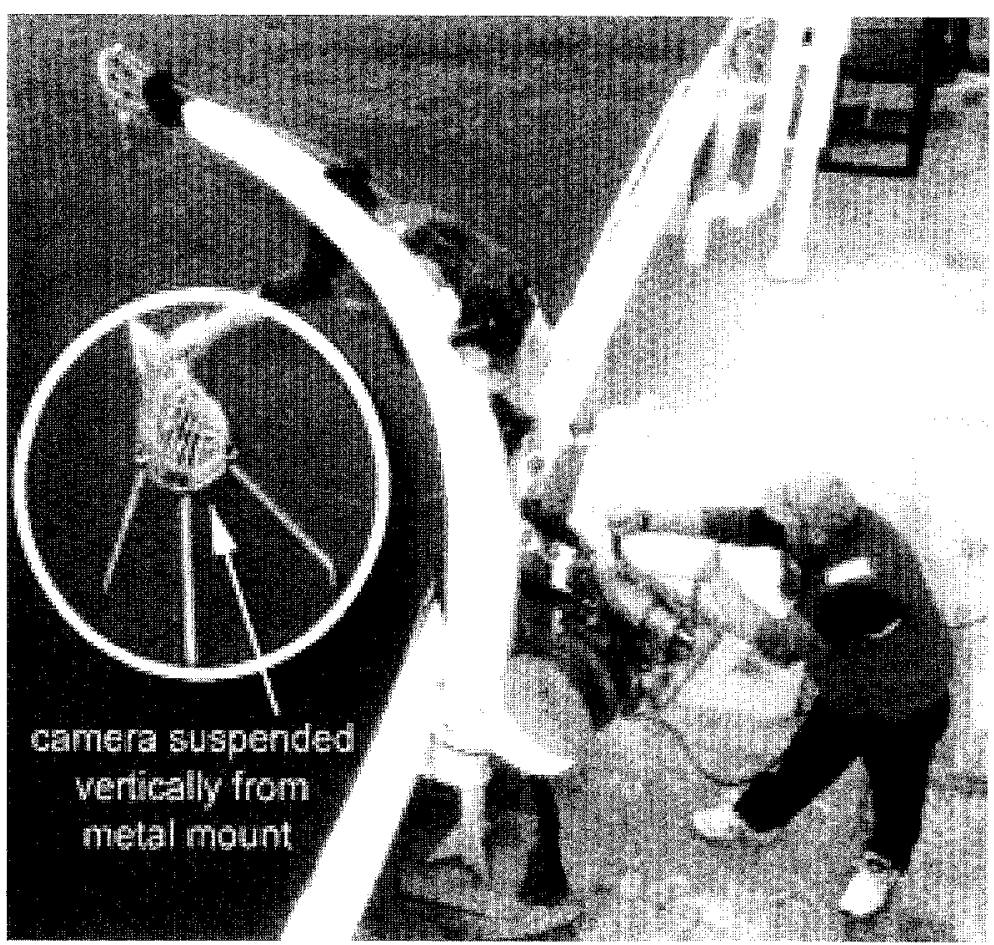

Figure 3. MAFRI drop video system - data source for this research. Source: Mr. R. Roob, MAFRI, Queenscliff, Victoria.

the southern Australian coastline [8]. With such a high biodiversity, the algae were split into two dominant assemblages: large brown algae - henceforth referred to as kelp; and a grouping of smaller algal forms. Sponges created the final dominant assemblage.

Dominant kelp species included Phyllospora comosa, Ecklonia radiata, Sargassum sp. and Durvillea potatorum. The forms of smaller algae included red, green and small brown species, with red algae being the most abundant. Species identified included Acrocarpia sp., Caulerpa flexilis, Caulerpa brownii, Delisea sp., Corallina officinalis and other Corallina sp. Sponge species were also considered dominant, with samples found in both shallow and deeper waters. Sponge specimens are difficult to identify under any circumstances, as they are known to change their form and colour depending on the conditions [1, 12], therefore, no attempt was made to identify dominant sponge species.

\subsection{Depth relationships}

By plotting the frequency distribution of each class against the depth variable, relationships between the habitat class and depth could be viewed. Figure 5 shows the distribution of the three dominant assemblages for the entire data-set with varying depth.

The most dense kelp cover was found in the shallowest waters, down to $20 \mathrm{~m}$. The only dense kelp found below this depth was at $27 \mathrm{~m}$. Moderate kelp cover was also found in shallow regions, extending to just $23 \mathrm{~m}$. The sites containing sparse kelp were in the 20 to $40 \mathrm{~m}$ depth range, with one site at $53 \mathrm{~m}$ having an extremely sparse kelp distribution.

The distribution of smaller algae was broader than kelp, with dense small algae found at depths from 7 to $35 \mathrm{~m}$. Moderate and sparse algal densities extended to $56 \mathrm{~m}$.

Sponge cover extended to a depth of $78 \mathrm{~m}$. Moderate to sparse sponge communities were located between 13 and $56 \mathrm{~m}$, with dense sponge life present to $78 \mathrm{~m}$ depth.

\subsection{Substrate relationships}

The samples were then grouped according to their hard substrate material. The frequency and density of each dominant assemblage was graphed against the depth for each substrate type. The distribution of occurrences for individual and mixed substrates could then be compared to determine if the ecology was influenced primarily by 

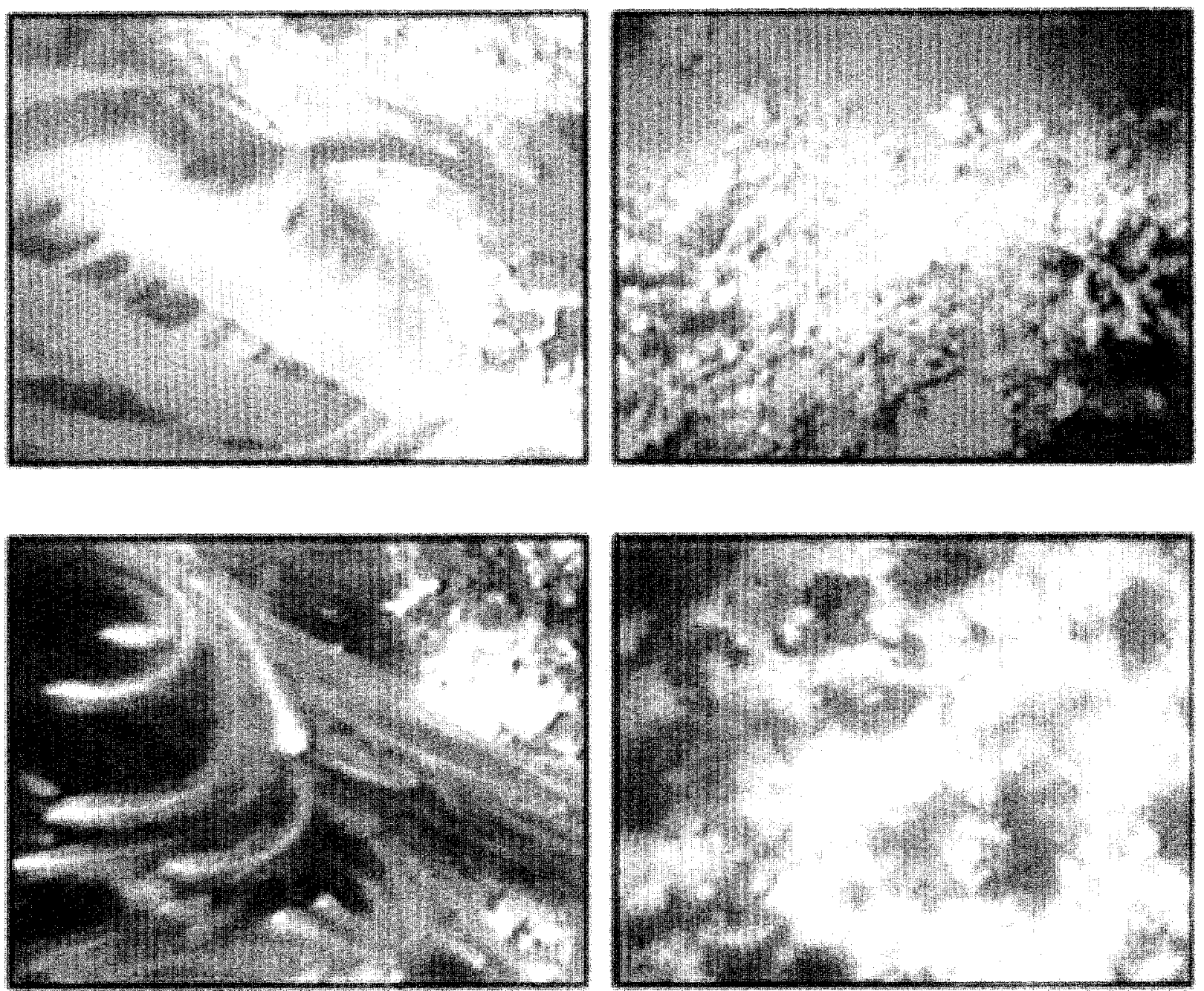

Figure 4. Examples of species belonging to the three dominant assembiages, being large brown algae or kelp (a), sponges (b), and smalter algae including both red and green species (c) and (d).

depth or substrate type. This procedure was undertaken to eliminate substrate type as a variable.

Limestone and sandstone substrates could not be included for comparisons as they had a total of only four samples. Five sites primarily comprising sandy substrates contained small algae, two of which at depths below $40 \mathrm{~m}$ also had sponge cover. No kelp species were visible on sand substrates. No additional data was available to determine if there was an underlying hard structure when vegetation was present on these sandy substrates, so they have not been included in graphical represcntations of specics distribution with respect to substrate type.
Figures 6,7 and 8 show the graphical representation of assemblage frequency and density with respect to depth for the basalt, granite and calcarenite substrate types. These geologies, particularly calcarenite and granite, have been selected for further analysis based on their high number of samples, and on the range of depths and species present in the samples.

\subsection{Basalt}

Nine of the 85 samples had basalt substrates. All of these samples were in relatively shallow waters, from depths of 9 to $31 \mathrm{~m}$. Seven of the nine samples had kelp species 


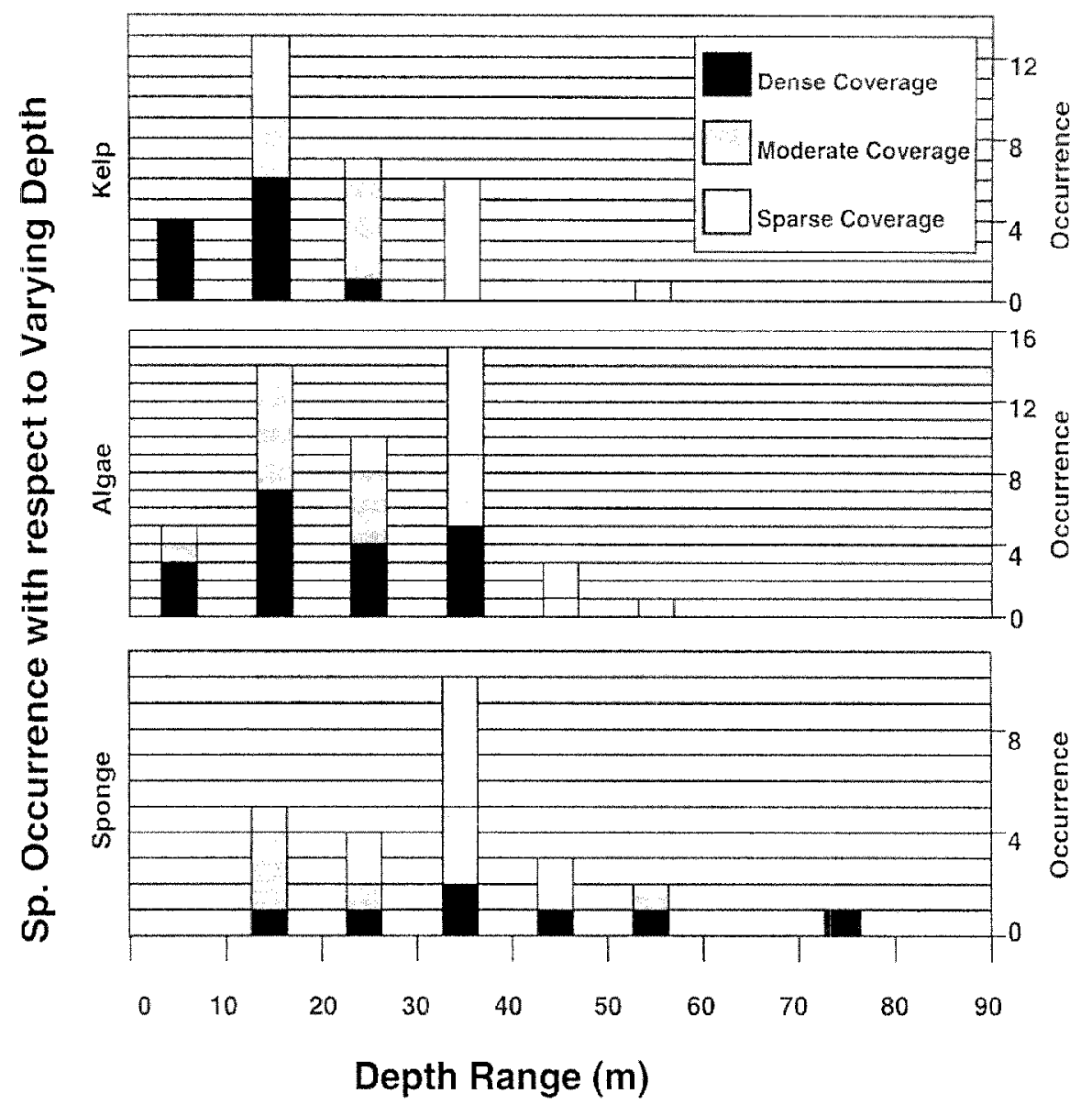

Figure 5. Graphical representation of the occurrence of the three dominant assemblages with respect to depth. The presence of each assemblage was semi-quantified by noting it as sparse, moderate or dense coverage. Total of 56 sites.

present. Moderate to dense small algae was also found at six of these sites, with encrusting algae present in most cases. One basalt site contained species from all of the dominant assemblages identified elsewhere. At this site, kelp was present in a sparse distribution, small red and brown algae along with sponges with moderate coverage. Figure 6 shows the species distribution for basaltic substrates.

\subsection{Granite}

The depth range of the 17 granite substrate sites was 7 to $87 \mathrm{~m}$. Moderate to dense kelp was found at 10 sites with a depth range of 7 to $23 \mathrm{~m}$, with very sparse cover found at two additional sites at 19 and $38 \mathrm{~m}$. Sparse sponge cover was also found at two relatively shallow sites, 20 and $23 \mathrm{~m}$, with moderate to very dense cover at depths rang- ing from 11 to $78 \mathrm{~m}$. Small algal species were present at 12 of the granite sites, with a depth range of 7 to $39 \mathrm{~m}$ for all densities. The species distribution for granite substrates is shown in figure 7.

\subsection{Calcarenite}

Calcarenite substrates were found at 21 sites, with the depth of these sites ranging from 6 to $56 \mathrm{~m}$. Over half of these sites had interstitial sand. Dense kelp was found at depths up to $9 \mathrm{~m}$, moderate kelp cover up to $22 \mathrm{~m}$ and sparse cover up to $53 \mathrm{~m}$. Small algae were spread over the entire depth range, dense algae from 6 to $32 \mathrm{~m}$, and moderate and sparse from 9 to $56 \mathrm{~m}$. Sponge cover was moderate to dense from $25 \mathrm{~m}$ up to $56 \mathrm{~m}$, and sparse from 30 to $50 \mathrm{~m}$. Figure 8 shows the calcarenite substrate species distribution. 


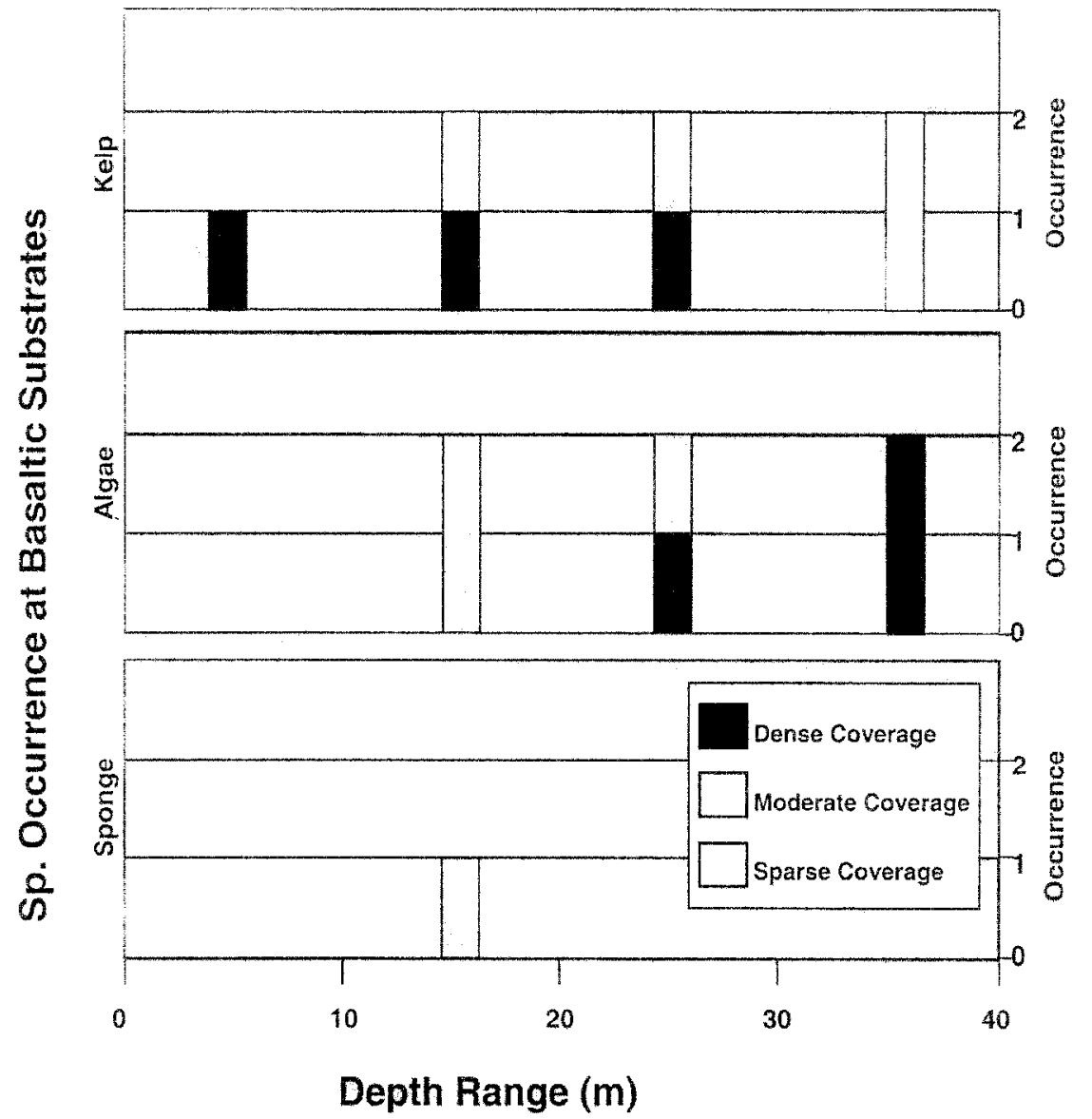

Figure 6. Graphical representation of the occurrence of the three dominant assemblages with respect to depth for basait substrates. Limited samples resulted in few conclusions drawn from analysis of this substrate type. Total of nine basalt sample sites.

\section{DISCUSSION}

\subsection{Distribution of dominant assemblages at varying depths}

As with previous studies concerning species distribution and depth in temperate Australia, the 5-35 $\mathrm{m}$ depth range was dominated by kelp species, such as Ecklonia radiata [8]. The green Caulerpa species along with small red algae were also abundant in these shallow waters. Below $35 \mathrm{~m}$, large kelp species gave way to the deeper-dwelling red algal species. However, as was found in this study, some kelp-like species (such as Sargassum sp.) may be found at up to $50 \mathrm{~m}$ depth in clear water [8].

Although the majority of sponge species are also found in relatively shallow waters, they are able to survive in waters where light has little or no penetration [4].

\subsection{Influence of substrate type versus depth}

The data obtained from the 56 drop video samples of Victorian waters do not show any obvious variation between kelp, small algal or sponge cover for different hard substrate types. When shown in graphical form, the distribution of the dominant assemblages on each hard substrate type appears to be close to their distribution with respect to depth, with the exception of basalt. The basalt sites appeared to have a higher percentage of kelp than other substrate types, however, this is likely to be due to the limited sample number and the shallow nature of these sites. Volcanic activity in Victoria was centred north of the numerous faults that run along the Victorian coastline, therefore most basalt lava flows were on land [2]. Some basaltic flows ran into the coastal area and cooled to form what is now the substrate of shallow Victorian waters. Therefore, the high percentage of kelp cover on basalt substrates may be due to the shallow Vic- 


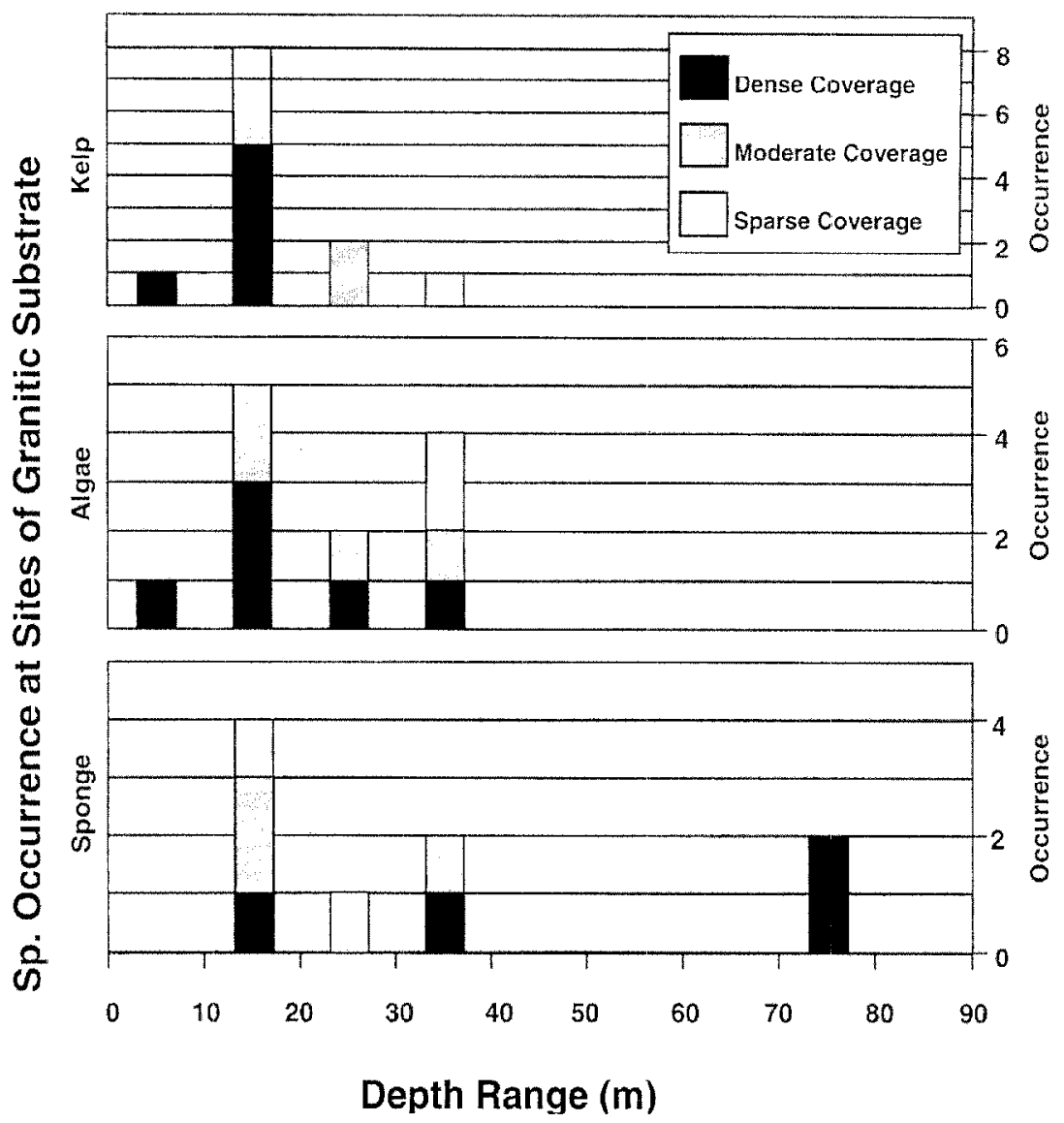

Figure 7. Graphical representation of the occurrence of the three dominant assemblages with respect to depth for granitic substrates. The graphs show the presence of both algal assemblages in shallow waters, with no depth trend for the sponge assemblage for this substrate. Total of 17 granite substrate sites.

torian basalt geology. This would indicate that the high kelp percentage is a function of depth rather than due to a preference for basaltic substrate types. No other sample substrate type appeared to have a distribution of dominant assemblages which varied greatly from the distribution with respect to depth.

\subsection{Limiting factors for dominant assemblages}

The above results indicate that depth has a greater influence on the distribution of the species investigated than does substrate type. Water clarity and depth influence the amount of light available for photosynthesis, and thus limit the survival depths of species that rely on this process for energy, such as the species in the kelp and small algae assemblages. High densities of kelp and other algal species were found only in shallow waters; as in Victorian waters light is limited to just a few tens of metres. In contrast, sponges rely on filter feeding for energy produc tion rather than photosynthesis, so do not have the same depth limitations as many algal species [1]. Sponge species thrive in areas with strong water movement, therefore the movement of particulates is a greater limiting factor to filter feeders than light [12].

The hard substrate type becomes a limiting factor when the weathering rate is considered, as this influences the anchorage of the species. Weathering patterns resulted in dense, diverse growth only on the boulders or slabs, with limited growth on interstitial sand. Of the 17 granite substrates observed, 15 consisted of huge boulders or slabs with interstitial sand. The remaining granite sites had pebbled substrates, providing enough hard substrate for full species coverage. The granite boulders had dense coverage on the tops, with the dominant species altering along the sides of the boulder, mimicking the depth effect. Calcarenous substrates tended to weather as hard, rocky reefs with interstitial sand, once again with dense coverage on the reef and limited macro-spccics on the sand. Basalt weathering was commonly in the form of 


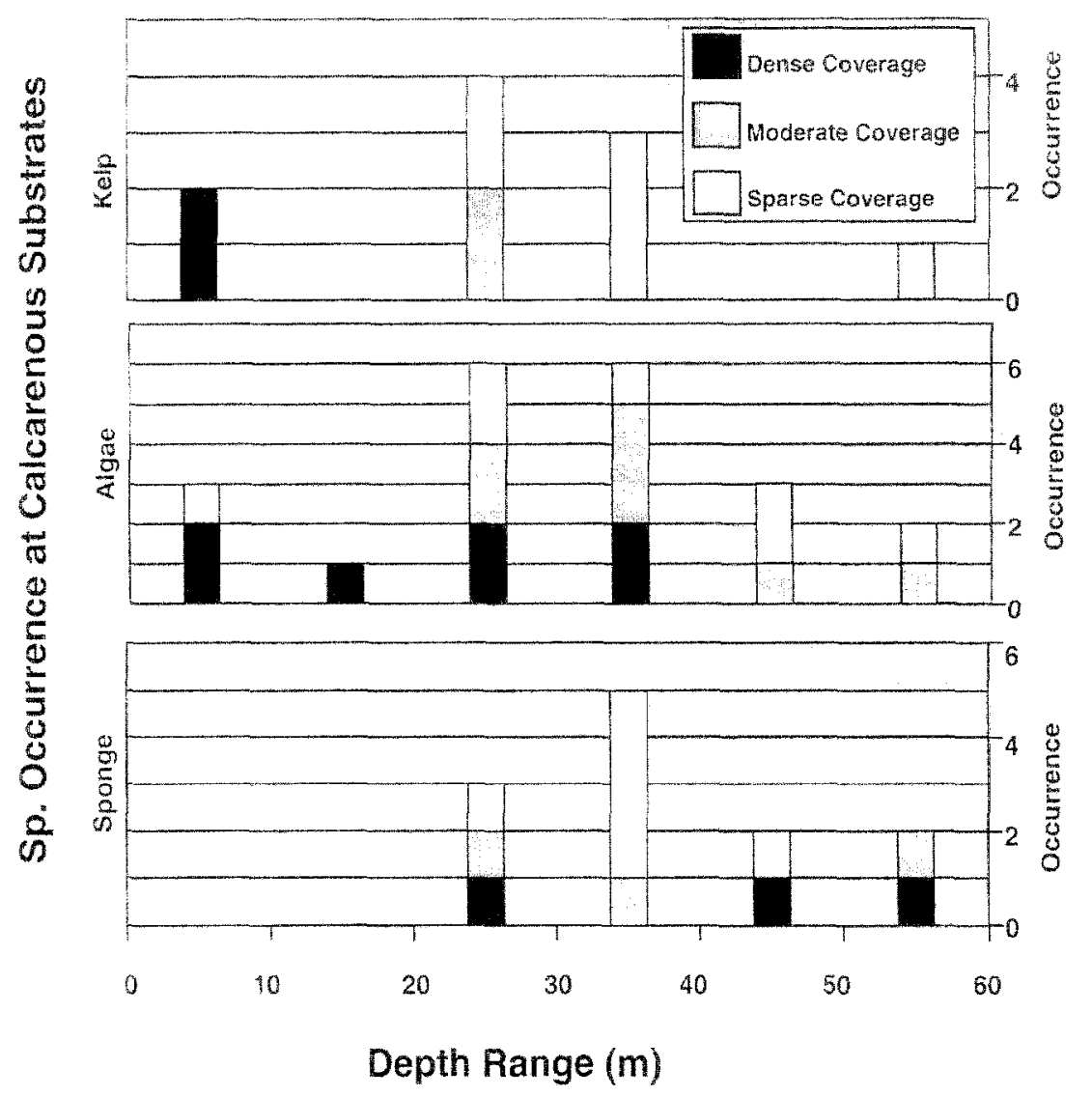

Figure 8. Graphical representation of the occurrence of the three dominant assemblages with respect to depth for calcarenous substrates. The graphs show a trend for both algal assemblages to dominate in shallow waters. Total of 21 samples sites with calcarenous substrates.

large cobbles, providing a more constant coverage in a large area as there was little interstitial sand. The coverage was less dense however, as the cobbles provide a more dynamic substrate due to potential turning.

Although the nature of the substrate does affect the longterm species coverage of an overall site, depth appears to be a greater limiting factor as it influences the photosynthetic processes of many sessile floral species.

\section{CONCLUSIONS}

ATV has commonly been used for qualitative marine studies, and its advantages in this field are numerous. The most obvious advantages are the availability and cost of the technology [14], with the equipment costing only a fraction of many other varieties of sampling equipment and methods. In contrast to diving, which is often the only other viable sampling method for low budget research, towed video safely provides data at depths limited by system design features rather than safety, provides platform stability suitable for more accurate measurements, and provides much greater coverage [3]. The dataintensive nature of the technique is also an important feature, as multiple frames can be grabbed each second and stored in digital format, with the original data available for further analysis at a later date [16].

The full potential of ATV has not yet been realised. The utility of the data is limited by problems such as camera orientation, image referencing and scale, radial lighting drop-off and camera calibration. This study has shown that ATV can be utilised in semi-quantitative studies of macro epi-benthos. ATV has the potential to be used for accurate quantitative studies if solutions were found to problems posed [16], such as camera orientation, image referencing and scale, radial lighting drop-off and camera calibration. Information that can be obtained through the quantitative use of ATV is diverse, making it an inexpensive tool for the study of sessile marine objects and other resources. 


\section{Acknowledgements}

The authors would like to acknowledge MAFRI for supplying ATV data. They also would like to thank Ralph Roob of MAFRI along with Vicki Wadley and Bruce
Barker of the CSIRO for their valuable technical input on the operational function of ATV systems and their discussion of the image results. Special thanks also go to Tim O'Hara from the Museum of Victoria for his help with the identification of marine flora and fauna.

\section{REFERENCES}

[1] Bennett I., Australian Seashores, Sydney, Angus and Robertson, $1992,266 \mathrm{p}$.

[2] Bird E.C.F., The Coast of Victoria, Melbourne, Melbourne University Press, 1993, 324 p.

[3] Harvey E., Shortis M., A System for Stereo-Video Measurement of Sub-Tidal Organisms, Mar. Tech. Soc. J. 29 (4) (1995/96) 10-22.

[4] Heezen B., Hollister C.D., The Face of the Deep, U.S.A., Oxford University Press, 1971, $659 \mathrm{p}$.

[5] LCC Marine and Coastal Special Investigation, Descriptive Report, Melbourne, Land Conservation Council, 1993.

[6] LCC Marine and Coastal Special Investigation, Proposed Rccommendations and Conservation Council, 1995.

[7] Li R. et al., Quantitative Photogrammetric Analysis of Digital Underwater Video Imagery, IEEE J, Ocean Engin. 22 (2) (1997) 364-375.

[8] Luning K., Seaweeds, Their Environment, Biogeography, and Ecophysiology, Canada, John Wiley \& Sons, 1990, 527 p.

[9] Magorrian B.H., Service M., Clarke W., An Acoustic Bottom Classification Survey of Strangford Lough, Northern Ireland, J. Mar. Biol. Ass. U.K. 75 (1995) 987-992.

[10] Magorrian B.H., Service M., Analysis of Underwater Visual Data to Identify the Impact of Physical Disturbance on Horse
Mussel (Modiolus modiolus) Beds, Mar. Poll. Bull., 36 (5) (1998) 354-359.

[11] Roob R., Currie D., Marine \& Coastal Special Investigation, Offshore Survey of Selected Areas, Victorian Hisheries Research Institute, Melbourne, 1996.

[12] Shepherd S.A., Thomas I.M. (Eds.), Marine Invertebrates of Southern Australia Part 1., Woolman D.J., South Australia, $1982,491 \mathrm{p}$.

[13] Singh H., Howland J., Yoerger D., Quantitative Photomosaicking of Underwater Imagery, in Occans 98, Nice, Francc, 1998, pp. 263-266.

[14] Wadley V., Barker B., Video and Still Photugraphy of the Seafloor Habitat of the South East Fishery, in AMSA '96, Hobart, Australia, Australian Marine Science Association, 1996.

[15] Williams I.M., Leach J.H.J., Along Track Video for Ocean Data Sampling, Problems and Possible Solutions, in Ocean Data Symposium Abstracts Volume, Dublin, Ireland, 1997, $47 \mathrm{p}$.

[16] Williams I.M., Leach J.H.J., Along Track Video for Ocean Data Sampling, Problems and Possible Solutions, in Ocean Data Symposium Proceedings, Dublin, Ireland, 1997, Paper pw4a. 